Goldschmidt 2021 Abstract

https://doi.org/10.7185/gold2021.4515

\section{First inference of molecular Hydrogen in mantle pyroxene and isotopic consequences}

\author{
BERTRAND N MOINE ${ }^{1}$, NATHALIE BOLFAN- \\ CASANOVA $^{2}$, IOANA-BOGDANA RADU ${ }^{3}$, DMITRI \\ IONOV $^{4}$, GELU COSTIN $^{5}$, ETIENNE DELOULE ${ }^{6}$, ANDREY \\ $\mathrm{V} \mathrm{KORSAKOV}^{7}$, ALEXANDER GOLOVIN $^{8}$ AND JEAN \\ YVES COTTIN $^{9}$ \\ ${ }^{1}$ Université Jean Monnet-CNRS \\ ${ }^{2}$ CNRS \\ ${ }^{3}$ Swedish Museum of Natural History \\ ${ }^{4}$ CNRS-UMR5243, Géosciences Montpellier, Université de \\ Montpellier \\ ${ }^{5}$ Rice University \\ ${ }^{6} \mathrm{CRPG}-\mathrm{CNRS}-\mathrm{UL}$ \\ ${ }^{7}$ V.S. Sobolev Institute of Geology and Mineralogy of the \\ Siberian Branch of the RAS \\ ${ }^{8}$ Institute of Geology and Mineralogy SB RAS \\ ${ }^{9}$ Université Jean Monnet - CNRS \\ Presenting Author: bertrand.moine@univ-st-etienne.fr
}

Hydrogen plays a key role in the evolution, dynamics and habitability of the Earth. It was primarily incorporated into the Earth's interior during its accretion and then evolved through degassing and recycling. Hydrogen is a ubiquitous trace component of nominally anhydrous minerals (NAMs) in the upper mantle, estimated to amount to $0.5-1$ times the total mass of the oceans. So far, hydrogen was known to exist in NAMs in the form of $\mathrm{OH}$, with storage capacity varying with depth. However, studies of cratonic mantle xenoliths indicate that $f \mathrm{O}_{2}$ ranges from FMQ -2 to -4.5 , conditions under which a substantial amount of hydrogen may be present in a reduced form $\left(\mathrm{H}_{2}\right)$. Experimental data suggest that $\mathrm{H}_{2}$ could be present in NAMs, however it is difficult to detect due to its low infrared extinction coefficient. We show that molecular hydrogen $\left(\mathrm{H}_{2}\right)$ coexists with $\mathrm{OH}$ in natural omphacite in eclogite xenoliths from the Siberian craton $\left(4-5 \mathrm{GPa}, 1100{ }^{\circ} \mathrm{C}\right)$, suggesting that $\mathrm{H}_{2}$ plays a role in water recycling to deep mantle.

Hydrogen isotope ratios ( $\partial \mathrm{D}$ values) in our samples increases with decreasing water content; contrary to previous inferences that $\partial \mathrm{D}$ decreases during subduction dehydration. The presence of $\mathrm{H}_{2}$ can explain the extremely negative values due to the positive fractionation between fluids and $\mathrm{H}_{2}$ and these counterintuitive relationships can be explained by the coexistence of $\mathrm{OH}$ and $\mathrm{H}_{2}$ in minerals. This better explains the relations between $\partial \mathrm{D}$ estimates for MORB-source convective upper mantle (about $-50 \%$ ) and glass inclusions in phenocrysts from plume basalts (down to $-218 \%$ ) that were previously attributed to a primitive deep reservoir or to contamination by recycled partially dehydrated oceanic crust.

Since molecular $\mathrm{H}_{2}$ is most likely to be the dominant form of hydrogen in the reduced deep mantle, it follows that $\mathrm{H}$ isotopic fractionation should be controlled by equilibria involving $\mathrm{H}_{2}-$ bearing minerals rather than $\mathrm{H}_{2} \mathrm{O}$ - or $\mathrm{OH}$-bearing minerals. This must be taken into account when interpreting hydrogen isotopic distribution in the mantle, as well as partitioning and isotopic exchange of hydrogen between the hydrosphere and the deep mantle. 